\title{
Expectativas dos utentes na consulta nos cuidados de saúde primários
}

Margarida Aroso, ${ }^{1}$ Pedro Seabra ${ }^{1}$

\section{RESUMO}

Objetivos: Caracterizar as expectativas dos utentes face à consulta de medicina geral e familiar (MGF) e analisar se existe relação entre o cumprimento das expectativas do utente e as características sociodemográficas, com a satisfação no final da consulta.

Métodos: Consistiu num estudo observacional transversal, realizado numa Unidade de Saúde Familiar (USF) durante quatro semanas. Os utentes que se dirigiam a uma consulta programada eram questionados sobre o interesse em responder a um inquérito anónimo. A primeira página, lida e preenchida antes da consulta, consistiu em dados sociodemográficos (idade, género, escolaridade), número de consultas que teve na USF no último ano e expectativas presentes antes da consulta. A segunda página, respondida após a consulta, consistiu num questionário para analisar as expectativas cumpridas na consulta e outro para avaliar a satisfação com os cuidados médicos.

Resultados: Obtiveram-se 65 inquéritos válidos. Verificou-se que a expectativa mais frequente antes da consulta consistia em receber informação sobre os resultados dos exames auxiliares de diagnóstico e a expectativa mais cumprida foi a explicação sobre o tratamento. Quanto ao grau de satisfação no final da consulta, a média de satisfação foi de 4,2 em 5 pontos. Verificou-se que os utentes estavam mais satisfeitos com o grau de confidencialidade e a forma como o médico o/a ouviu. Observou-se maior grau de satisfação em utentes com grau de escolaridade superior, com maior número de expectativas cumpridas e com maior número de ações realizadas e que não eram expectativas que o doente levava para a consulta.

Conclusões: É importante identificar as expectativas que os doentes levam para a consulta, pois os utentes que reportam elevado número de expectativas cumpridas têm um elevado nível de satisfação, o qual pode ser atualmente considerado como um importante indicador da qualidade de saúde.

Palavras-chave: Expectativas; Satisfação; Cuidados de saúde primários.

\section{INTRODUÇÃO}

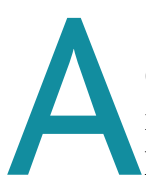

relação médico-doente tem sido descrita como a pedra angular da medicina geral e familiar (MGF) e está estabelecido que uma relação mais produtiva e efetiva ocorre quando o médico compreende as principais preocupações dos doentes. ${ }^{1}$ A expressão das necessidades dos doentes é uma dimensão essencial no processo de comunicação, existindo um reconhecimento crescente da importância das expectativas dos doentes em MGF. ${ }^{2}$ Um dos primeiros passos para o estabelecimento da aliança médico-doente é a identificação das expectativas face à consulta e, por expectativa, entende-se aquilo que o

1. USF Pedras Rubras, ACeS Maia-Valongo. Maia, Portugal. utente deseja ou julga que vai acontecer durante a consulta. ${ }^{3}$ Uma expectativa pode ser uma necessidade, solicitação ou desejo antes de se encontrar com o médico e que é depois expressa sob a forma de uma afirmação, uma questão ou como um pedido. ${ }^{4}$ Constrói-se a partir de fatores pessoais como a natureza dos sintomas, perceção da vulnerabilidade à doença, experiências anteriores e conhecimentos adquiridos. ${ }^{5}$

Pacientes com maior número de expectativas atendidas relatam satisfação significativamente superior com a consulta. ${ }^{4,6} \mathrm{O}$ grau de satisfação pode ter repercussões no seu estado funcional e clínico: doentes cujas expectativas não são atendidas relatam menos melhoria do seu estado de saúde, menos intenção de adesão ao tratamento e mais contactos com o sistema de 
saúde pós-consulta. ${ }^{7}$ Assim, a satisfação do doente é atualmente considerada como um importante indicador de qualidade de saúde, tal como a qualidade de vida, mortalidade e custos de saúde. ${ }^{8}$

O objetivo deste trabalho foi caracterizar as expectativas dos utentes face à consulta de MGF de uma Unidade de Saúde Familiar (USF), identificar a relação entre o cumprimento das expectativas do utente e a satisfação com a consulta e analisar se existe relação entre características sociodemográficas e a satisfação com a consulta.

\section{MÉTODOS}

Este trabalho consistiu num estudo observacional transversal, realizado na USF Pedras Rubras, do Agrupamento de Centros de Saúde Maia-Valongo.

Durante quatro semanas, todos os utentes que se dirigiam à USF para uma consulta programada, com mais de 18 anos e com capacidade para ler e escrever, foram questionados pelas assistentes administrativas sobre $o$ interesse em responder a um inquérito anónimo (Anexo I) e cujo objetivo seria melhorar a qualidade dos serviços prestados. No caso de resposta positiva, o inquérito era fornecido e explicado que a primeira página devia ser lida e preenchida antes da consulta e a segunda página após a consulta. $\mathrm{O}$ inquérito era respondido na sala de espera e, no final, depositado numa urna colocada no balcão da receção. Assumiu-se o consentimento quando o inquérito era respondido e, no caso da existência de dúvidas, as assistentes administrativas forneciam auxílio. Foi definido pelos autores que seriam distribuídos 115 inquéritos, o que correspondia a $1 \%$ da amostra da população da USF com mais de 18 anos no momento da realização do estudo.

A primeira página consistiu na colheita dos dados sociodemográficos (idade, género, escolaridade), número de consultas que teve na USF no último ano e as expectativas presentes antes da consulta. A idade foi categorizada em dois grupos: 1) igual ou maior de 18 anos e inferior a 50 anos; 2 ) igual ou maior a 50 anos. O grau de escolaridade foi dividido em quatro grupos: 1) sabe ler/escrever ou completou o $1^{\circ}$ ciclo ensino básico; 2) completou o $2^{\circ} / 3^{\circ}$ ciclo de ensino básico; 3 ) completou o ensino secundário/médio; 4) completou o ensino superior. Quanto ao número de consultas que teve no último ano na USF este foi categorizado em três grupos:
1) zero ou uma consulta; 2) duas a três consultas; 3 ) quatro ou mais consultas no ano.

Para avaliação das expectativas antes da consulta foram construídas, pelos autores, nove afirmações que traduzem as expectativas que lhes parecem ser mais frequentes na população portuguesa, sendo o questionário de Williams e colaboradore $s^{4} \mathrm{o}$ ponto de partida. As nove afirmações que constituíram esta parte do inquérito agrupam-se em três grandes grupos: 1) testes e diagnóstico;2) suporte;3) explicação. As respostas consistiam em «Espero», «Não sei» e «Não espero». Os autores assumiram, como expectativa presente antes da consulta, sempre que respondiam «Espero».

A segunda página do inquérito, respondida após a consulta, consistia em nove frases para perceber que expectativas tinham sido cumpridas na consulta, segundo a perspetiva do doente, e cujas respostas eram «Concordo», «Assim-assim»e «Discordo». Os autores assumiram, como expectativa cumprida na consulta, sempre que respondiam «Concordo». De seguida, os participantes responderam a 17 afirmações, que tiveram por base o questionário EUROPEP validado para a língua portuguesa, ${ }^{9}$ e cuja resposta correspondia à seguinte pontuação: 0) Não se aplica; 1) Mau; 2) Médio mau; 3) Médio; 4) Médio bom; e 5) Excelente. O objetivo foi avaliar a satisfação com os cuidados médicos através de quatro dimensões: relação médico-paciente; cuidados médicos; informação e apoio; organização dos serviços. Os autores assumiram que o utente estava satisfeito quando respondia «5-Excelente» ou «4-Médio bom»; medianamente satisfeito quando respondia «3-Médio»; e não satisfeito se respondia "2-Médio mau» ou «1-Mau». Os resultados foram interpretados de acordo com a média da pontuação dada para cada item.

Os questionários que tinham questões por responder eram excluídos.

Para registo e análise da informação foram utilizados os programas informáticos Microsoft Office Excell $2016{ }^{\circledR}$ e IBM SPSS Statistics 2015®. Para a comparação entre grupos foi utilizado o teste Mann-Whitneye para medir a associação foi utilizado o coeficiente de correlação de Spearman. Foi definido um nível de significância de $5 \%$.

\section{RESULTADOS}

Durante quatro semanas consecutivas foram entregues 
115 Inquéritos entregues a utentes com consulta programada, com mais de 18 anos e com capacidade para ler e escrever

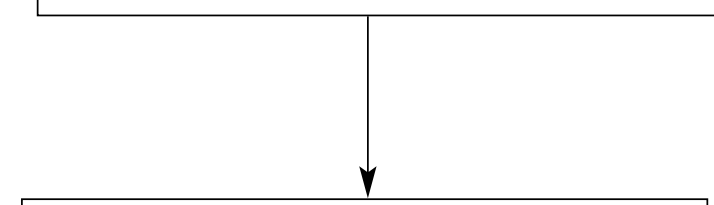

86 Inquéritos depositados na urna do balcão

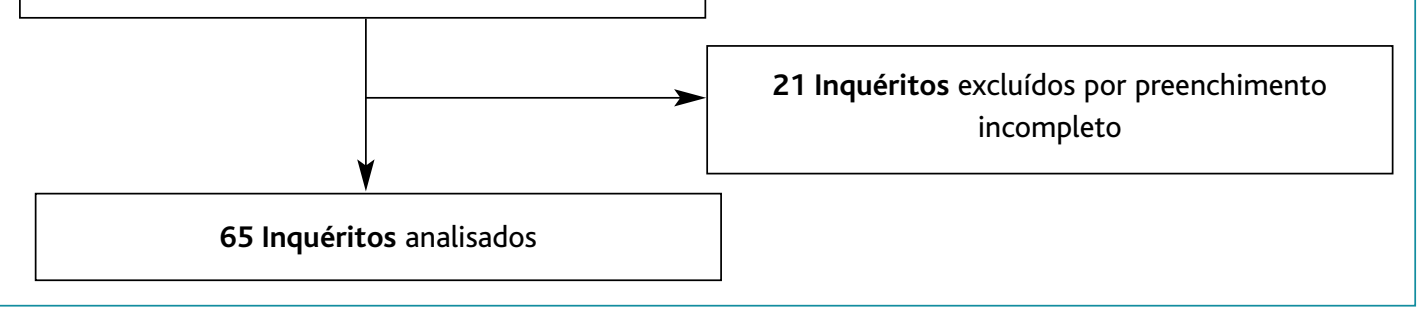

Figura 1. Fluxograma amostral.

\begin{tabular}{|c|c|}
\hline Características dos indivíduos & Total $(N=65)$ \\
\hline \multicolumn{2}{|l|}{ Idade, $n(\%)$} \\
\hline$\geq 18$ e $<50$ anos & $38(58,5)$ \\
\hline$\geq 50$ anos & $27(41,5)$ \\
\hline \multicolumn{2}{|l|}{ Género, $n$ (\%) } \\
\hline Feminino & $35(53,8)$ \\
\hline Masculino & $30(46,2)$ \\
\hline \multicolumn{2}{|l|}{ Escolaridade completa, $n$ (\%) } \\
\hline Saber ler/escrever ou completaram $1^{\circ}$ ciclo & $2(3,1)$ \\
\hline $2^{\circ}$ ou $3^{\circ}$ ciclo & $19(29,2)$ \\
\hline Ensino secundário/médio & $29(44,6)$ \\
\hline Ensino superior & $15(23,1)$ \\
\hline \multicolumn{2}{|l|}{ Consultas no último ano, $n(\%)$} \\
\hline 0 ou 1 consulta & $16(24,6)$ \\
\hline 2 a 4 consultas & $24(36,9)$ \\
\hline$\geq 5$ consultas & $25(38,5)$ \\
\hline
\end{tabular}

115 inquéritos, tendo sido respondidos e devolvidos 86 (75\%). Vinte e um inquéritos não foram analisados por estarem preenchidos de forma incompleta, restando 65 inquéritos para análise (Figura 1).
A Tabela 1 apresenta os resultados sociodemográficos dos participantes e respetivo número de consultas.

Considerando a resposta «Espero» ao questionário sobre as expectativas, realizado antes da consulta, observou-se que os utentes levaram para a consulta 384 expectativas, uma média de 5,9 expectativas por utente. Sete utentes levavam as nove expectativas do questionário e dois utentes não levavam qualquer uma. Verificou-se que $56(86,0 \%)$ indivíduos esperavam receber informação sobre os resultados dos exames auxiliares de diagnóstico, 54 (83,0\%) indivíduos esperavam que o seu médico explicasse a sua doença/os seus sintomas e o mesmo número de indivíduos esperavam que o médico lhes explicasse o tratamento (e.g., posologia, duração de tratamento, consultas de seguimento). A Figura 2 apresenta a taxa de prevalência de cada tipo de expectativa.

Contabilizando o total de respostas ao questionário de expectativas realizado após a consulta, observou-se que houve $332(67,4 \%)$ expectativas realizadas nas consultas e uma taxa global de cumprimento de $66,4 \%$.Vinte e três utentes viram cumpridas todas as expectativas e nove utentes não viram qualquer uma cumprida. As expectativas mais realizadas foram a explicação sobre o tratamento $(79,6 \%)$, o suporte para os problemas (76,3\%) e a explicação sobre a doença/sintomas $(74,1 \%)$ (Figura 3). 


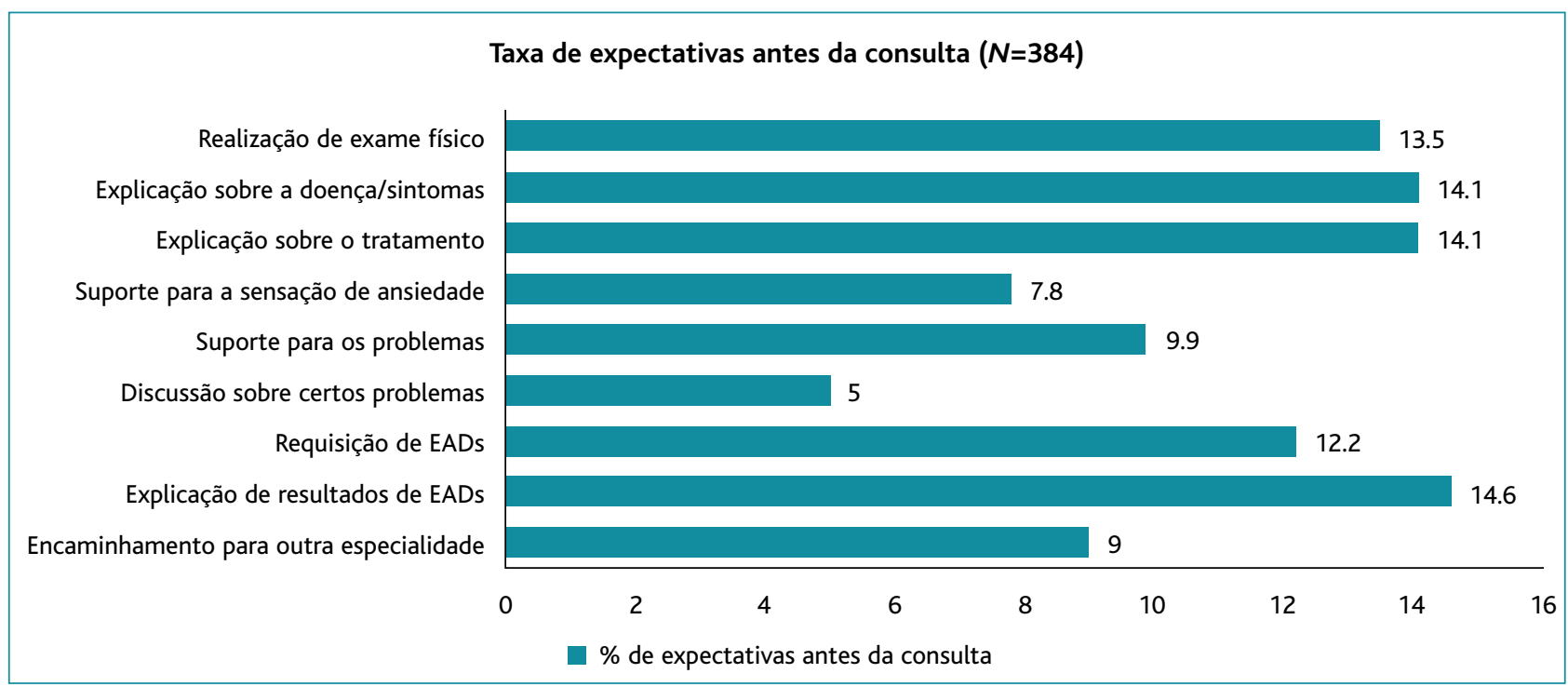

Figura 2. Taxa de expectativas dos utentes antes da consulta.

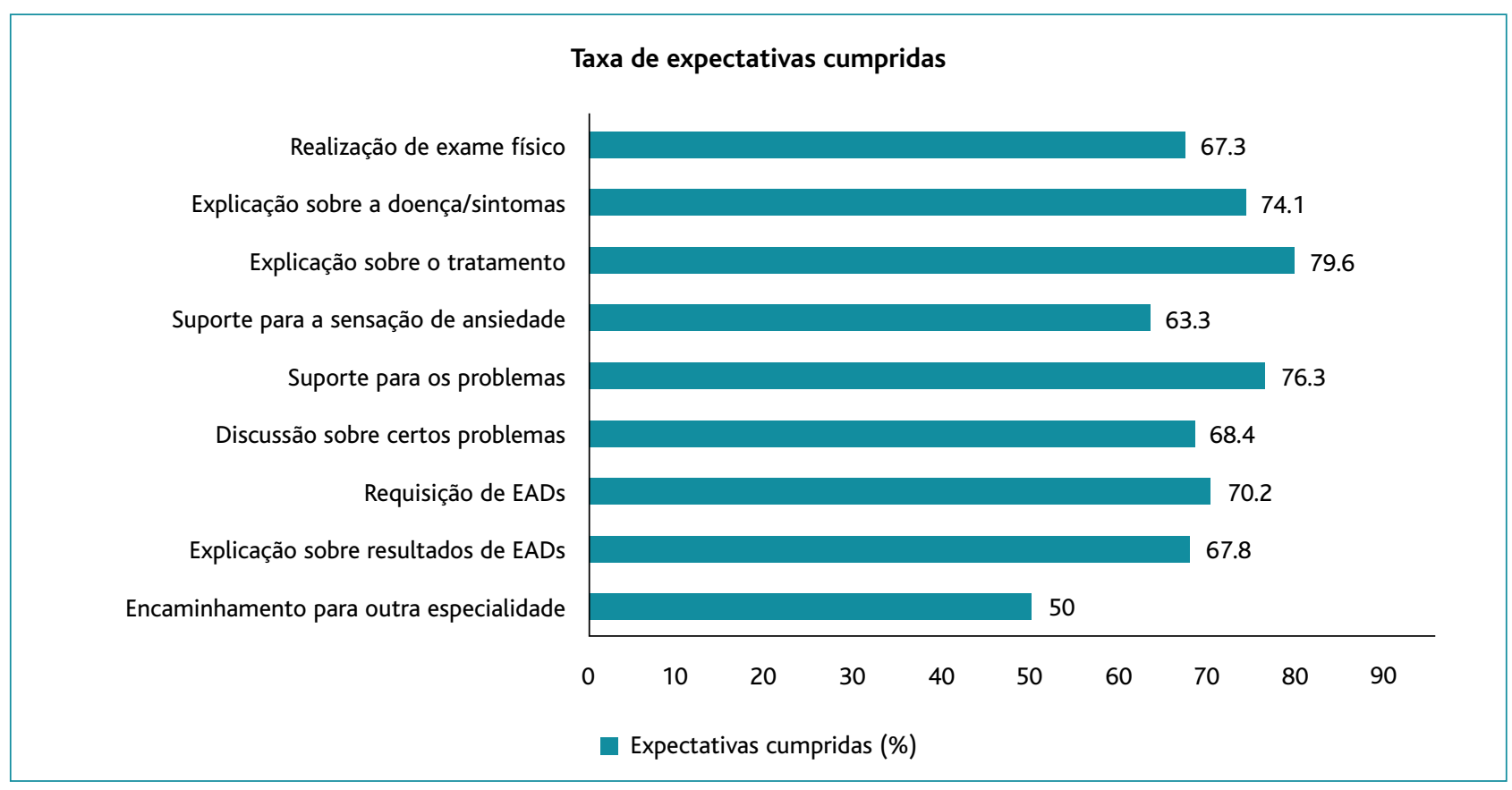

Figura 3. Taxa de expectativas cumpridas na consulta.

Ficaram por cumprir 119 (30,9\%) expectativas, com uma média de 1,9 expectativas não cumpridas por utente. O encaminhamento para outra especialidade $(55,9 \%)$, suporte para a sensação de ansiedade $(36,7 \%)$ e realização de exame físico $(32,7 \%)$ foram as menos cumpridas (Figura 4). Também se identificaram 57 ações (procedimento realizado pelo médico e que não era expectativa do doente) cumpridas na consulta. As mais prevalentes foram a ajuda do médico por se sentir ansioso $(n=11)$, o suporte para os problemas $(n=10)$, a discussão sobre certos problemas de vida $(n=9)$ e o pedido de exames auxiliares de diagnóstico $(n=9)$. 


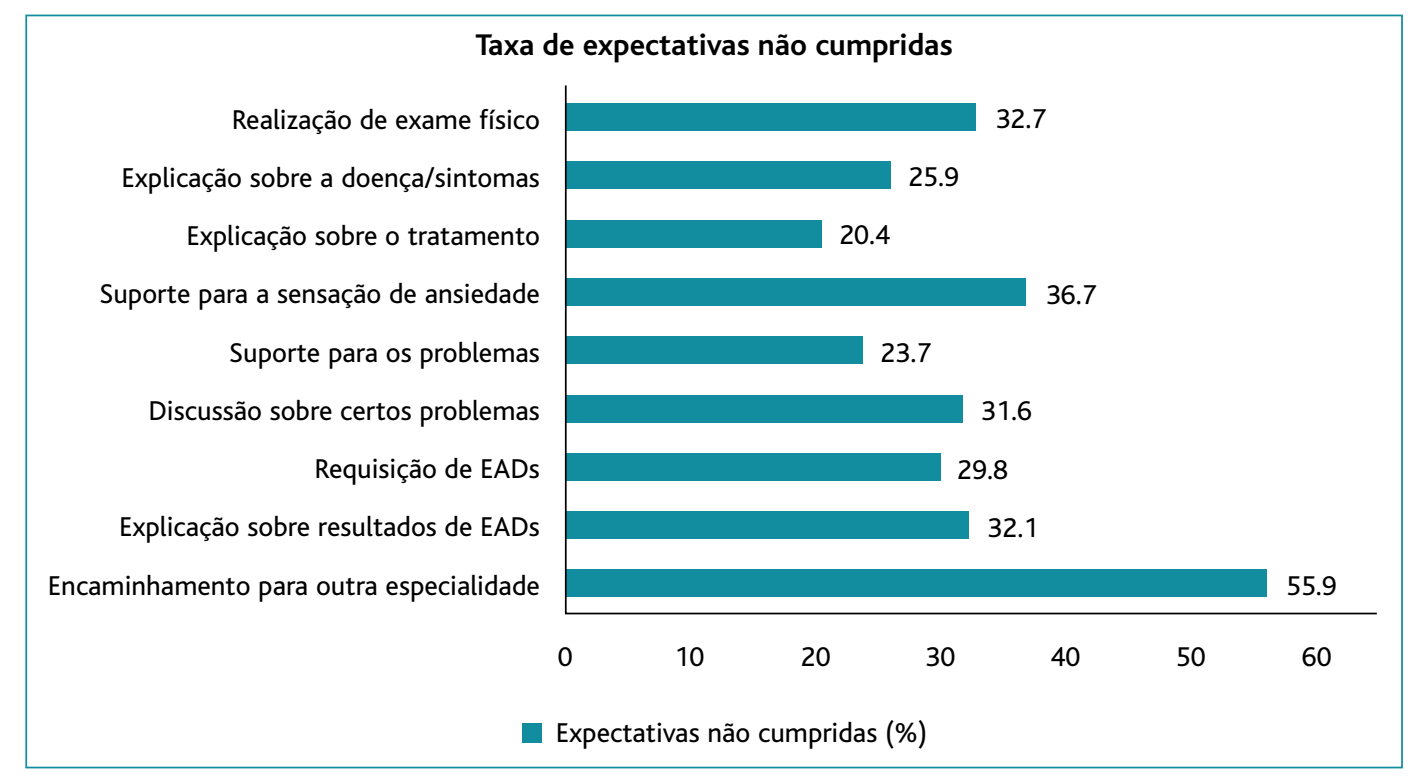

Figura 4. Taxa de expectativas não cumpridas na consulta.

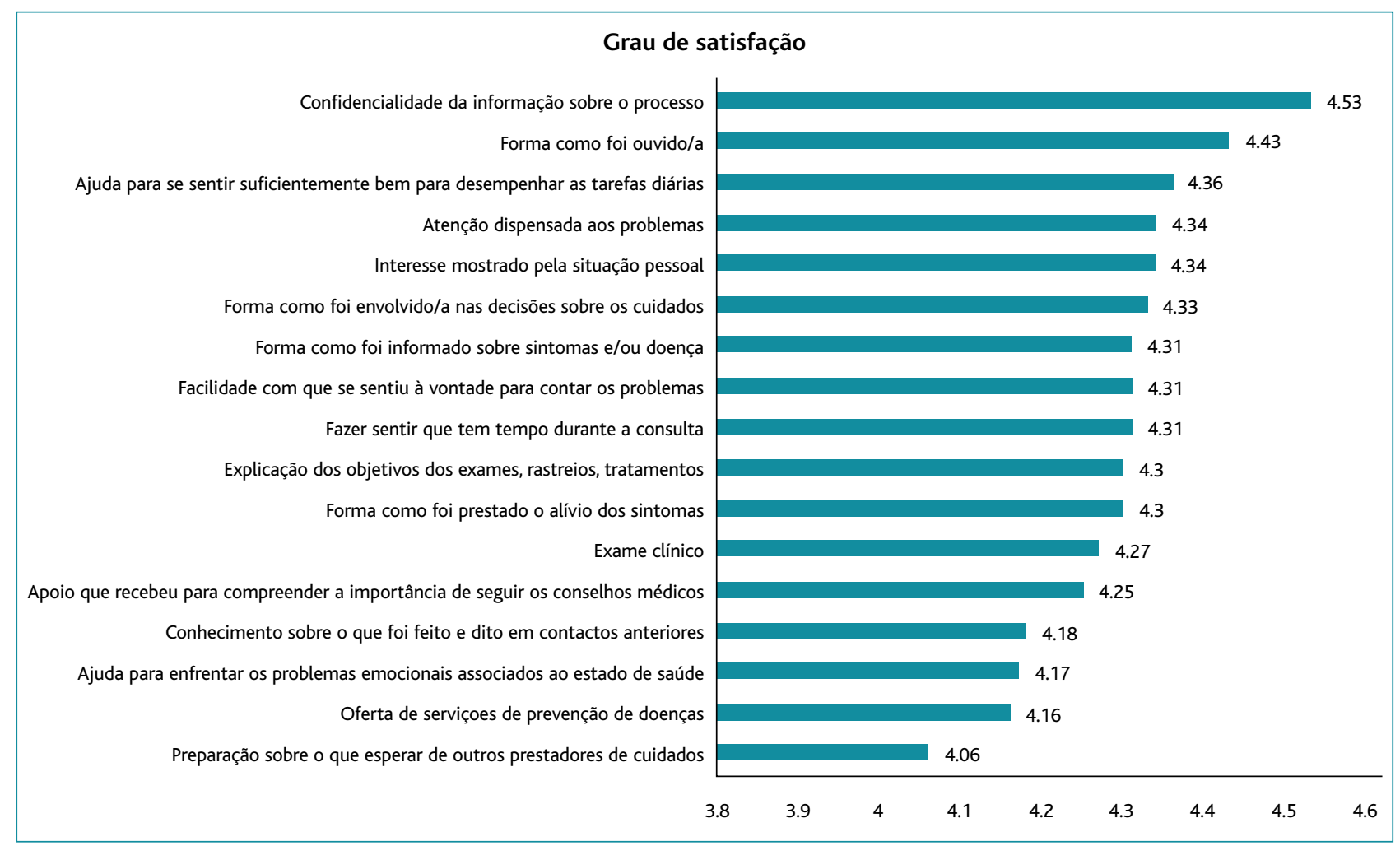

Figura 5. Média do grau de satisfação da consulta.

A média de satisfação no final da consulta foi de 4,2 em 5 pontos, explorado através do último questionário sobre a avaliação que faz do médico. Vinte e sete utentes deram a pontuação máxima em todas as 
afirmações, tendo-se registado maior satisfação com o grau de confidencialidade $(4,5)$, forma como o médico o/a ouviu $(4,4)$ e a ajuda que recebeu para desempenhar as tarefas diárias $(4,4)$ (Figura 5). Os autores observaram a inexistência de relação entre este parâmetro e a idade dos utentes $(p=0,65)$, o género $(p=0,43)$ e o número de consultas no último ano $(p=0,79)$. No entanto, constatou-se que a satisfação variou com o grau de escolaridade $(p=0,04)$, como observado na Figura 6: o nível de satisfação é maior nos graus de escolaridade superior.

Há evidência estatística suficiente para afirmar que a satisfação está correlacionada com o número de expectativas cumpridas $(\rho=0,36 ; p<0,01)$, constatando-se uma correlação linear positiva e moderada.

Também se verificou evidência estatística suficiente para afirmar que o grau de satisfação está correlacionado com o número de ações realizadas e que não eram expectativas que o doente levava para a consulta $(\rho=0,26 ; p<0,05)$, com uma correlação linear positiva baixa.

\section{DISCUSSÃO}

Este estudo permitiu perceber quais eram as expectativas dos utentes antes da consulta, quais foram cumpridas e o grau de satisfação no final da consulta, através do preenchimento de um inquérito que teve uma taxa de adesão de $75 \%$, número este similar ao trabalho de Zebiene e colaboradores ${ }^{6}$ e Pinto e colaboradores. ${ }^{10}$ As expectativas mais desejadas estavam associadas a informação e explicação. O grau de satisfação no final da consulta foi elevado, tendo-se verificado que existe uma relação direta entre o número de expectativas cumpridas e a satisfação, como foi observado noutros estudos., ${ }^{4,610} \mathrm{O}$ número de ações realizadas, mas que não eram expectativas antes da consulta, também esteve relacionado com o grau de satisfação dos utentes.

Analisando a relação entre dados sociodemográficos e número de consultas realizadas no último ano, apenas se verificou que quanto mais elevada é a escolaridade maior é a satisfação no final da consulta. Esta relação poder-se-á dever ao facto destes utentes terem mais capacidade para expressar as suas expectativas ou por questionarem e exigirem mais.

As expectativas mais desejadas estavam associadas a informação e explicação, muito similares às observa-

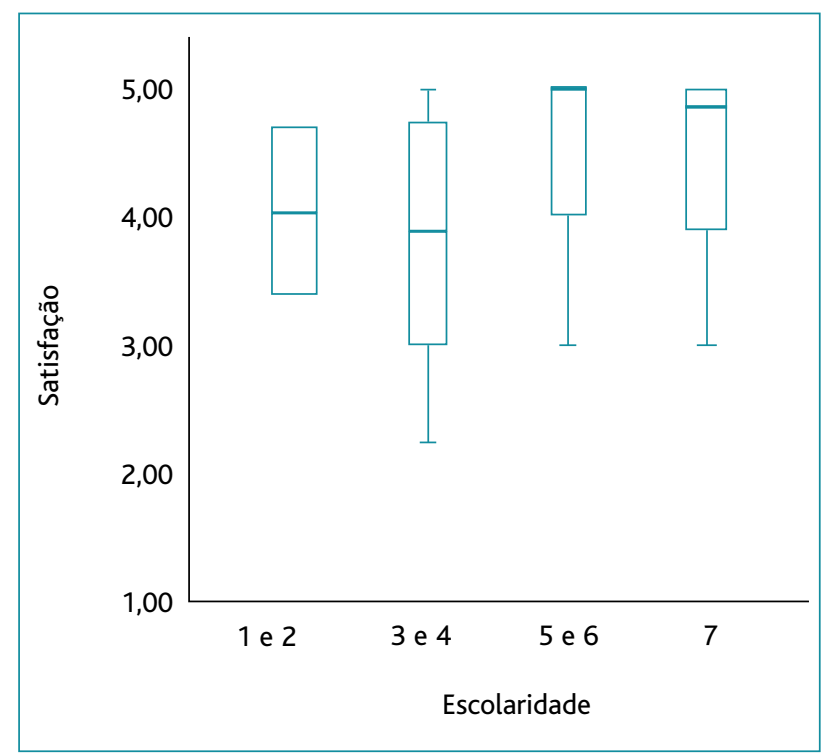

Figura 6. Relação entre o grau de satisfação e a escolaridade (teste de Kruskal-Wallis).

das noutros estudos nacionais e internacionais, ${ }^{4,10} \mathrm{de}$ monstrando que para os utentes é mais importante a informação biomédica do que os aspetos psicossociais da consulta.

Observou-se que 267 (80,6\%) expectativas foram cumpridas, sendo este valor semelhante a outros trabalhos $^{6,10}$ e uma taxa global de cumprimento de $66,4 \%$. Quanto às expectativas desejadas, mas não cumpridas, verificou-se uma média de 1,9 expectativas não cumpridas por utente, ficando por satisfazer $119(36,0 \%)$ expectativas, muito acima dos $7 \%$ reportados por Zebiene e colaboradores ${ }^{6}$ e dos 11,6\% de Bell e colaboradores. ${ }^{7}$ Estes dados podem resultar de o doente falhar em expressar esse desejo ou, quando expresso, ser inadequado para a apresentação do problema. Pode ainda dever-se ao médico não ter conhecimento total sobre a situação para poder explicar ou, até mesmo, por falta de tempo. À semelhança de um estudo nacional, ${ }^{10}$ a referenciação para outra especialidade foi a expectativa menos cumprida.

O oposto também se verificou: existiram 63 ações que ocorreram na consulta e que não refletiam expectativas. As mais frequentes pertenceram à categoria de suporte, o que pode indicar que o doente não espera/exige este suporte do médico de família, mas apenas ações de características técnicas. 
Quanto aos resultados do questionário que reflete a satisfação do utente verificou-se que a média de satisfação foi de 4,2 num total de 5 pontos (84,6\%), o que os autores consideram como elevado. Registe-se que 27 utentes classificaram a satisfação com a pontuação máxima.

Estes resultados refletem a opinião dos utentes, podendo variar consoante a capacidade com que a pessoa expressa os seus desejos, o tipo de relação médico-doente existente e o papel de negociação por parte do médico durante a consulta. Além do mais, os inquéritos limitam a oportunidade dos utentes expressarem os seus interesses sobre diferentes aspetos dos cuidados de saúde e podem ter um conjunto complexo de crenças importantes que não são reveladas em termos de satisfação simples. Assim, os autores não podem aplicar as conclusões deste estudo a todos os utentes dos cuidados de saúde primários. Deve também ser considerada a dificuldade em separar vários aspetos da consulta que estão associados, por exemplo, nem sempre a explicação pode estar totalmente separada do suporte emocional. Esta limitação reflete a complexidade e diferentes aspetos da arte da medicina.

Uma das principais limitações deste estudo é o processo de amostragem que leva a algum risco de viés: foram as técnicas administrativas que por seu livre-arbítrio entregaram os inquéritos e, por vezes devido à escassez de tempo, a explicação sobre o questionário pode não ter sido a mais esclarecedora. Também a distribuição por género, idade e escolaridade não foi homogénea. Dado que apenas foram avaliados 65 inquéritos, os dados obtidos podem não ser representativos da opinião de todos os utentes e os inquéritos são preenchidos pelos utentes que vêm à USF, podendo não expressar a opinião da totalidade da população.

Os questionários que avaliaram as expectativas antes e após a consulta foram construídos pelos autores com base em vários estudos semelhantes nacionais $\mathrm{e}$ internacionais, pelo que não foram validados, podendo existir diferenças culturais importantes e a exclusão de expectativas características dos utentes portugueses. Também não foi aplicado inicialmente, como pré-teste, num grupo à parte.

Como sugerido noutros trabalhos, seria importante desenvolver um método fiável e validado de avaliação das expectativas para a população portuguesa. Este tipo de inquéritos, simples na sua aplicação, permitem o conhecimento das expectativas e da satisfação do doente, o que é fundamental para a melhoria dos cuidados de saúde primários numa perspetiva centrada no paciente, podendo ser usados como método de auditoria pelos próprios médicos.

É também importante clarificar que fatores podem modificar o nível de satisfação dos utentes portugueses por forma a que se traduza em ganhos para a saúde.

\section{CONCLUSÃO}

Este estudo concluiu que os utentes da USF em estudo tinham um elevado nível de satisfação após a consulta. Esta satisfação está diretamente relacionada com o número de expectativas cumpridas, assim como o número de ações realizadas que não eram expectativas. No entanto, quase todos os utentes saíram da consulta com uma expectativa não realizada, sendo as mais desejadas a explicação e informação durante a consulta.

A satisfação do utente pode ter repercussões no seu estado funcional e clínico, nomeadamente na perceção do estado de saúde, na adesão ao tratamento e menos contactos com o sistema de saúde pós-consulta. Desta forma, os autores entendem que seria importante desenvolver um método fiável e validado de avaliação das expectativas para a população portuguesa, pois o conhecimento das mesmas e da satisfação é fundamental para a melhoria dos cuidados de saúde primários.

\section{REFERÊNCIAS BIBLIOGRÁFICAS}

1. Strasser R. The doctor-patient relationship in general practice. Med J Aust. 1992;156(5):334,338.

2. Salmon P, Sharma N, Valori R, Bellenger N. Patients' intentions in primary care: relationship to physical and psychological symptoms and their perception by general practitioners. Soc Sci Med. 1994;38(4):58592.

3. Kravitz RL. Measuring patients' expectations and requests. Ann Intern Med. 2001;134(9 Pt 2):881-8.

4. Williams S, Weinman J, Dale J, Newman S. Patient expectations: what do primary care patients want from the GP and how far does meeting expectations affect patient satisfaction? Fam Pract. 1995;12(2):193-201.

5. Kravitz RL, Callahan EJ, Paterniti D, Antonius D, Dunham M, Lewis CE. Prevalence and sources of patients' unmet expectations for care. Ann Intern Med. 1996;125(9):730-7.

6. Zebiene E, Razgauskas E, Basys V, Baubiniene A, Gurevicius R, Padaiga $Z$, et al. Meeting patient's expectations in primary care consultations in Lithuania. Int J Qual Health Care. 2004;16(1):83-9.

7. Bell RA, Kravitz RL, Thom D, Krupat E, Azari R. Unmet expectations for 
care and the patient-physician relationship. J Gen Intern Med. 2002;17 (11):817-24.

8. Bovier P, Künzi B, Stalder H. Qualité des soins en médecine de premier recours: «à l'écoute de nos patients». Rev Med Suisse. 2006;2:31671.

9. Ferreira PL, Raposo V. Monitorização da satisfação dos utilizadores das USF e de uma amostra de UCSP: relatório final. Coimbra: Centro de Estudos e Investigação em Saúde da Universidade de Coimbra; 2015.

10. Pinto D, Coutinho SS, Rezende C. Cumprimento de expectativas e satisfação com a consulta de medicina geral e familiar [Meeting expectations and patient satisfaction with family medicine office visits]. Rev Port Clin Geral. 2009;25(4):405-17. Portuguese

\section{CONFLITO DE INTERESSES}

Os autores declaram não possuir quaisquer conflitos de interesse.

\author{
ENDEREÇO PARA CORRESPONDÊNCIA \\ Margarida Aroso \\ E-mail: marososilva@gmail.com \\ https://orcid.org/0000-0001-5906-9510
}

Recebido em 16-07-2020

Aceite para publicação em 10-03-2021

\section{ABSTRACT}

\section{PATIENTS' EXPECTATIONS IN THE PRIMARY HEALTH CARE APPOINTMENT}

Objective: To characterize expectations of the primary health care users, and to analyze whether there is a relationship between the fulfillment of the expectations and sociodemographic characteristics, with satisfaction at the end of the appointment.

Methods: It consisted of an observational longitudinal study, carried out in a primary care center for four weeks. Users who went to a scheduled appointment were asked about their interest in answering an anonymous inquiry. The first page, read and completed before the appointment, consisted of sociodemographic data (age, gender, education), number of appointments in the last year, and expectations present before the appointment. The second page, answered after the appointment, consisted of two questionnaires, one to analyze the expectations fulfilled in the appointment and the other to assess satisfaction with medical care.

Results: Sixty-five valid inquiries were obtained. It was found that the most frequent expectation before the appointment was to receive information about the results of the auxiliary diagnostic tests, and the most fulfilled expectation was the explanation about the treatment. The degree of satisfaction was 4.2 out of 5 points. It was found that users were more satisfied with the degree of confidentiality and the way he/she was heard. It was observed a greater degree of satisfaction in users with a higher level of education, with a greater number of fulfilled expectations, and with a greater number of actions performed and which were no expectations that the patient took to the appointment.

Conclusion: It is important to identify the expectations that patients take to the appointment, as users who report a high number of fulfilled expectations have a high level of satisfaction, which can currently be considered as an important indicator of health quality.

Keywords: Expectations; Satisfaction; Primary health care. 


\section{ANEXO I \\ Questionário das expectativas pré-consulta}

Por favor, preencha os dados seguintes a seu respeito:

Idade: Género: Feminino

Masculino

Que grau de ensino é que completou?
1. Só sabe ler/escrever
2. $1 .^{\circ}$ ciclo do ensino básico $\left(1 .^{\circ}-4 .^{\circ}\right.$ ano)/antiga $4 .^{a}$ classe
3. $2 .^{\circ}$ ciclo do ensino básico $\left(5 .^{\circ}\right.$ e $6 .^{\circ}$ ano)/antiga $6 .^{a}$ classe

4. 3. ${ }^{\circ}$ ciclo do ensino básico $7 .^{\circ}-9 .^{\circ}$ ano)/curso geral dos liceus

5. Ensino secundário $\left(10 .^{\circ}-12 .^{\circ}\right.$ ano)/ensino complementar dos liceus

6. Ensino médio

7. Ensino superior (politécnico ou universitário)

Quantas consultas médicas teve na USF no último ano?

\section{Questionário de expectativas pré-consulta}

Pedimos que nos diga o que espera ou gostaria que acontecesse na sua consulta de hoje e não o que acha importante nas consultas em geral ou o que espera numa das próximas consultas. Em relação a cada uma das perguntas existem três hipóteses de resposta. Deve assinalar aquela que the parece mais adequada de acordo com o que espera para a consulta de hoje.

\begin{tabular}{|c|c|c|c|}
\hline & Espero & Não sei & Não espero \\
\hline \multicolumn{4}{|l|}{$\begin{array}{l}\text { 1. Eu espero que o meu médico me faça uma observação física (ex., auscultar, ver a } \\
\text { garganta, medir a tensão arterial...) e descubra o meu problema }\end{array}$} \\
\hline \multicolumn{4}{|l|}{ 2. Eu espero que o meu médico me explique a minha doença/as minhas queixas } \\
\hline \multicolumn{4}{|l|}{$\begin{array}{l}\text { 3. Eu quero que o meu médico me explique o tratamento (ex., como tomar os } \\
\text { medicamentos, duração do tratamento, consultas de seguimento... }\end{array}$} \\
\hline \multicolumn{4}{|l|}{ 5. Eu espero suporte para os meus problemas } \\
\hline \multicolumn{4}{|l|}{ 6. Eu espero poder discutir certos problemas da minha vida } \\
\hline \multicolumn{4}{|l|}{$\begin{array}{l}\text { 7. Eu espero que o meu médico me peça exames (ex., análises de sangue, radiografia, } \\
\text { ecografia...) }\end{array}$} \\
\hline \multicolumn{4}{|l|}{ 8. Eu espero que o meu médico me explique os resultados dos exames } \\
\hline \multicolumn{4}{|l|}{$\begin{array}{l}\text { 9. Eu espero que o meu médico me envie para uma consulta de outra especialidade } \\
\text { (ex., dermatologia, cardiologia, fisiatria, ortopedia...) }\end{array}$} \\
\hline Pedimos que responda no final da consulta, às questões que estão no verso da folha. & & & \\
\hline
\end{tabular}

Pedimos que responda no final da consulta, às questões que estão no verso da folha.

\section{Questionário das expectativas pós-consulta}

Pedimos-lhe agora que nos responda a algumas perguntas sobre a forma como decorreu a sua consulta de hoje. Em relação a cada uma das perguntas existem três hipóteses de resposta. Deve assinalar aquela que lhe parece mais adequada.

\begin{tabular}{|c|c|c|c|}
\hline & Concordo & Assim-assim & Discordo \\
\hline $\begin{array}{l}\text { 1. O meu médico fez-me uma observação física (ex. auscultar, ver a garganta, medir a } \\
\text { tensão arterial...). }\end{array}$ & & & \\
\hline
\end{tabular}




\begin{tabular}{|c|c|c|c|}
\hline & Concordo & Assim-assim & Discordo \\
\hline \multicolumn{4}{|l|}{ 2. O meu médico explicou as minhas queixas/o que me preocupava. } \\
\hline \multicolumn{4}{|c|}{$\begin{array}{l}\text { 3. O meu médico explicou-me o tratamento (ex. como tomar os medicamentos, } \\
\text { duração do tratamento, consultas de seguimento...). }\end{array}$} \\
\hline \multicolumn{4}{|l|}{ 4. Sinto-me ansioso/a e o meu médico ajudou-me nesta consulta. } \\
\hline \multicolumn{4}{|l|}{ 5. O meu médico deu-me apoio para os meus problemas. } \\
\hline \multicolumn{4}{|l|}{ 6. Nesta consulta consegui conversar sobre certos problemas da minha vida. } \\
\hline \multicolumn{4}{|l|}{ 7. O meu médico pediu exames (ex. análises de sangue, radiografia, ecografia...). } \\
\hline \multicolumn{4}{|l|}{ 8. O meu médico explicou-me os resultados dos meus exames. } \\
\hline $\begin{array}{l}\text { 9. O meu médico enviou-me para uma consulta de outra especialidade } \\
\text { (ex. dermatologia, cardiologia, fisiatria, ortopedia...). }\end{array}$ & & & \\
\hline
\end{tabular}

\section{Questionário de Satisfação}

E por fim, que avaliação faz do seu médico de família em relação a:

\begin{tabular}{|c|c|c|c|c|c|c|}
\hline & Excelente & $\begin{array}{l}\text { Médio } \\
\text { Bom }\end{array}$ & Médio & $\begin{array}{l}\text { Médio } \\
\text { Mau }\end{array}$ & Mau & $\begin{array}{l}\text { Não se } \\
\text { aplica }\end{array}$ \\
\hline 1. Fazê-lo/a sentir que tem tempo durante a consulta. & 1 & 2 & 3 & 4 & 5 & 0 \\
\hline 2. Interesse mostrado pela sua situação pessoal. & 1 & 2 & 3 & 4 & 5 & 0 \\
\hline 3. À vontade que o/a deixou para contar os seus problemas. & 1 & 2 & 3 & 4 & 5 & 0 \\
\hline 4. Forma como o/a envolveu nas decisões sobre os cuidados. & 1 & 2 & 3 & 4 & 5 & 0 \\
\hline 5. Forma como o médico o/a ouviu. & 1 & 2 & 3 & 4 & 5 & 0 \\
\hline 6. Confidencialidade da informação sobre o seu processo clínico. & 1 & 2 & 3 & 4 & 5 & 0 \\
\hline 7. Forma como lhe foi prestado alívio dos seus sintomas/queixas. & 1 & 2 & 3 & 4 & 5 & 0 \\
\hline $\begin{array}{l}\text { 8. Ajuda que lhe prestou para se sentir suficientemente bem para realizar } \\
\text { as suas tarefas do dia-a-dia. }\end{array}$ & 1 & 2 & 3 & 4 & 5 & 0 \\
\hline 9. Atenção dispensada aos seus problemas. & 1 & 2 & 3 & 4 & 5 & 0 \\
\hline $\begin{array}{l}\text { 10. Observação física (ex. auscultar, ver a garganta, medir a tensão } \\
\text { arterial...). }\end{array}$ & 1 & 2 & 3 & 4 & 5 & 0 \\
\hline 11. Oferta de serviços de prevenção de doenças (ex. rastreios, vacinas). & 1 & 2 & 3 & 4 & 5 & 0 \\
\hline 12. Explicação dos objetivos de exames, rastreios, tratamentos. & 1 & 2 & 3 & 4 & 5 & 0 \\
\hline 13. Forma como foi esclarecido/a sobre a(s) sua(s) doença(s). & 1 & 2 & 3 & 4 & 5 & 0 \\
\hline $\begin{array}{l}\text { 14. Ajuda que recebeu para enfrentar os sentimentos associados ao meu } \\
\text { problema. }\end{array}$ & 1 & 2 & 3 & 4 & 5 & 0 \\
\hline 15. Explicação sobre a importância de seguir os conselhos do seu médico. & 1 & 2 & 3 & 4 & 5 & 0 \\
\hline 16. Conhecimento sobre o que foi feito e dito em anteriores contactos. & 1 & 2 & 3 & 4 & 5 & 0 \\
\hline $\begin{array}{l}\text { 17. Preparação sobre o que esperar de outras especialidades para as quais } \\
\text { fui encaminhado. }\end{array}$ & 1 & 2 & 3 & 4 & 5 & 0 \\
\hline
\end{tabular}

